\title{
Analysis of the oxidation process of powders and sinters of the austenitic stainless steel
}

\author{
Karolin Mazur ${ }^{1} \cdot$ Marek Hebda $^{1}$
}

Received: 16 August 2017 / Accepted: 24 February 2018/ Published online: 5 March 2018

(C) The Author(s) 2018. This article is an open access publication

\begin{abstract}
Nowadays, austenitic stainless steels due to its properties are widely used in various applications. In powder metallurgy technology, one of the key factors, affecting the pressing process, the sintering phenomena and the final properties of sintered parts, is the shape and particle size of the powders. The article presents the results focused on analysis of the oxidation process of austenitic stainless steel. Powders of the same chemical composition, however of different shapes, depending on the manufacturing technique, i.e. spherical after inert gas atomization and sponge after water atomization, were investigated. Moreover, the influence of particles' size from different ranges 40-56 and 80-100 $\mu \mathrm{m}$ on the oxidation behaviour was analysed. Thermal measurements, differential scanning calorimetry and thermogravimetry, were performed by the STA 409 CD (Netzsch) advanced coupling techniques. Moreover, dilatometry technique has been used for the analysis of the influence of the size and shape of particles on the sintering process. Sinters oxidation phenomena have also been determined. Based on the obtained results, it was found that both shape and size of powders have a significant influence on the oxidation processes of powders as well as sinters of the austenitic stainless steel.
\end{abstract}

Keywords Oxidation $\cdot$ Stainless steel $\cdot$ TG/DTG/DSC $\cdot$ Particle size $\cdot$ Particle shape

\section{Introduction}

Austenitic stainless steel (SS) has excellent anti-corrosion properties. Therefore, it is often used for the production of parts exposed to work in extreme conditions, such as increased temperature or harmful atmospheres. SS is widely used in a variety of: medical, heavy industry, precision mechanics and electronics applications, where it is often impossible to replace it with modern materials due to the operating conditions [1-8].

Nowadays, among the many methods of manufacturing powder metallurgy, due to economic and ecological aspects of production, it is one of the most intensively developed technologies. The properties of the final products depend on many factors. The most important is the chemical composition and the parameters used in the subsequent stages of the manufacturing process: mixing of powders,

Marek Hebda

mhebda@pk.edu.pl

1 Institute of Materials Engineering, Cracow University of Technology, Cracow, Poland forming and sintering. At each of these stages, the shape and particle size of the powders used in the manufacturing of the products has a significant impact [9-13]. For example, the morphology of the particles plays an important role in the process of forming, especially in die compacting, the most popular industrial process. Generally, powders of spherical shape compared to sponge are much more difficult to compact. This effect has a major influence on the reduction of the strength properties of sinter. Another factor, apart from the shape of the particles and their chemical composition, which has a main impact on the compacting as well as sintering process is the particle size. Moreover, dependent on the powder consolidation technique, it is required that their size is: (1) strictly defined, to a very narrow range, e.g. for MIM (metal injection moulding) or SLM (selective laser melting) method or (2) in a relatively wide range as for die compaction $[14,15]$.

The aim of the presented work was to investigate the influence of shape and size of austenitic stainless steel particles on the oxidation process and sintering 
phenomena. Moreover, the influence of particles' size and shape on the oxidation behaviour of sinters was also analysed.

\section{Materials and methods}

In this research, an austenitic stainless steel powder AISI 316L, supplied by Hoganas, was used. The chemical composition specified by the manufacturer is shown in Table 1.

Thermal measurements were taken with STA 409 CD (Netzsch) advance coupling techniques (DSC/TG). Two replicates were measured. The calorimetric curves were recorded with a differential scanning calorimeter using an alumina crucible, with about $20 \mathrm{mg}$ of samples under a dynamic air atmosphere $\left(80 \mathrm{~mL} \mathrm{~min}^{-1}\right)$. The temperature range was from 30 to $1300^{\circ} \mathrm{C}$ at a heating rate of $5,7.5,10$, 12.5, $15^{\circ} \mathrm{C} \mathrm{min}^{-1}$. The holding time at the isothermal temperature was kept at $60 \mathrm{~min}$. An empty alumina crucible was used as a reference. The apparatus was calibrated using indium, tin, bismuth, zinc, aluminium, silver and gold as a standard. The heat flow signal was calibrated by the melting heat of the above-mentioned elements. The DSC/TG data were analysed using Proteus software (ver. 5.2) from Netzsch. All of the presented curves were corrected against empty runs.

Moreover, analysis of sintering behaviour using the horizontal Netzsch $402 \mathrm{C}$ dilatometer was investigated on samples with a diameter of $5 \mathrm{~mm}$ and a height of $10 \mathrm{~mm}$. Green compacts were produced by uniaxial cold pressing at $600 \mathrm{MPa}$. The sintering process was performed in highpurity (99.999\%) hydrogen atmosphere with $100 \mathrm{~mL} \mathrm{m^{-1 }}$ flow rate. The heating and cooling rates were $10{ }^{\circ} \mathrm{C} \mathrm{min}{ }^{-1}$. The isothermal sintering temperature was $1250{ }^{\circ} \mathrm{C}$. The holding time at the isothermal sintering temperature was $30 \mathrm{~min}$.

The sieve analysis was performed on a Vibratory Sieve Shaker Analysette 3 Spartan Fritsch. The sieve size was 40, 56, 63, 71, 80, 100 and $160 \mu \mathrm{m}$. Measurements were taken according to PN-EN 24497 ISO 4497.

The morphology of the particles was observed by the JEOL JSM-5510LV scanning electron microscope. Microanalysis was performed by the application of an

Table 1 Chemical composition of 316L stainless steel Chemical composition/mass\%

\begin{tabular}{lllllllll}
\hline $\mathrm{Fe}$ & $\mathrm{C}$ & $\mathrm{Cr}$ & $\mathrm{Ni}$ & $\mathrm{Mo}$ & $\mathrm{Mn}$ & $\mathrm{Si}$ & $\mathrm{S}$ & $\mathrm{P}$ \\
\hline Bal. & 0.03 & $16-18$ & $10-14$ & $2-3$ & $<2$ & $<1$ & $<0.03$ & 0.04 \\
\hline
\end{tabular}

energy-dispersive spectrometer (EDS) IXRF Systems Model 500 Digital Processing.

The phase identification was performed by an X-ray diffraction apparatus D2 Phaser analyser manufactured by Bruker (anode: copper; step of measurement: $0.02^{\circ} ; 8 \mathrm{~s}$ per step). Diffraction data processing was carried out by EVA software. The phases were identified with PDF2 database.

\section{Results and discussion}

Figure 1 shows representative powder particle shapes that depend only on the manufacturing method used. The spheroidal particles identified in the article with symbol A are characteristic for the atomization process, a stream of molten steel, by an inert gas (Fig. 1a). On the other hand, the spongy particles designated as B are obtained after the water atomization process (Fig. 1b). The influence of the method of production on the shape of particles is well known and independent of the chemical composition of the materials produced [14, 16, 17]. The particle size distribution of powders A and B used in the studies is presented in Table 2. Based on the obtained results, it was found that the largest percentage share, regardless of the shape of powders, was fractions in the range 40-56 and 80-100 $\mu \mathrm{m}$. Since the particles from these fractions were the largest volume fraction and they differed from each other in size twice, they were selected for analysing the effect of particle size and shape on the oxidation process (Table 3 ).

Figure 2 shows the TG changes recorded during the oxidation of powders, depending on: (1) the size and shape of the austenitic stainless steel particles and (2) the heating rate. The onset and endset values determined from the curves are presented as summary graphs in Fig. 3. Based on the obtained results, it was found that regardless of the type of particles, a single-step oxidation process of the powders was observed. It always started at temperatures above $1060{ }^{\circ} \mathrm{C}$. It has also been observed that the onset of oxidation occurred at a temperature lower by about $60{ }^{\circ} \mathrm{C}$ for spongy-shaped powders compared to the results obtained for spheroidal powder. This effect was independent of particle size and heating rate. In addition, the increase in the particle size of the powder increased the temperature at which the oxidation process started. This effect was occurred at a temperature by about $10{ }^{\circ} \mathrm{C}$ higher for the spongy powder as compared to the spheroidal one. Also, as the heating rate increased, the temperature at which the oxidation started was increasing.

Mass of samples as a result of oxidation process increased in the range from 37 to $43 \%$. In general, for spheroidal particles, a larger mass growth was recorded than for spongy-shaped particles of similar size. The smallest mass increase was recorded for $80-100 \mu \mathrm{m}$ and 
Fig. 1 Shapes of $316 \mathrm{~L}$ austenitic stainless steel particles a spheroidal, b spongy
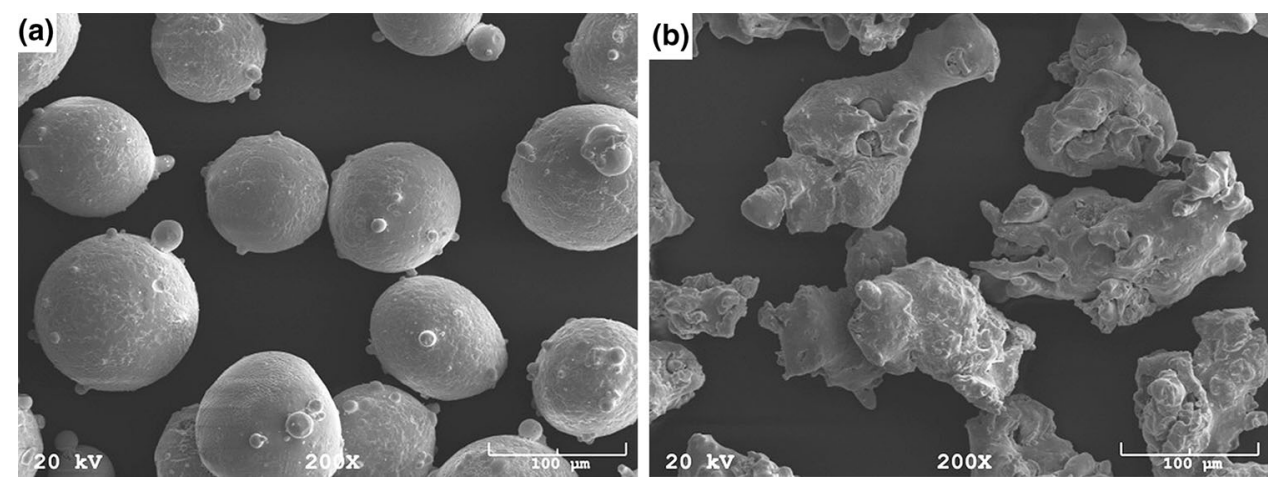

Table 2 Sieve analysis of A and B powders

\begin{tabular}{lll}
\hline Size mesh sieve/ $\mu \mathrm{m}$ & \multicolumn{2}{l}{ Percentage of powder on the sieve/\% } \\
\cline { 2 - 3 } & A (spherical) & B (sponge) \\
\hline$<40$ & 2.5 & 22.4 \\
40 & 38.6 & 30.3 \\
56 & 6.3 & 3.4 \\
63 & 14.0 & 7.7 \\
71 & 1.3 & 12.2 \\
80 & 37.3 & 24.0 \\
100 & 0 & 0 \\
160 & 0 & 0 \\
\hline
\end{tabular}

Table 3 Powdered samples selected according to the shape and particle size of the powder

\begin{tabular}{lll}
\hline Symbol of powder & Shape & Particles size $/ \mu \mathrm{m}$ \\
\hline A & Spherical & $40-56$ \\
& & $80-100$ \\
B & Sponge & $40-56$ \\
& & $80-100$ \\
\hline
\end{tabular}

spongy shape, while the largest for spheroidal particles in the range $40-56 \mu \mathrm{m}$.

Based on the DTG curves, the temperatures at which the oxidation process was characterized by the most violent waveforms were determined. These values were both dependent on the size and shape of the powder particles, as shown in Fig. 4. For heating rates above $5{ }^{\circ} \mathrm{C} \mathrm{min}^{-1}$ and spongy powder of $80-100 \mu \mathrm{m}$, the maximum oxidation intensity occurred at about $1180 \pm 5{ }^{\circ} \mathrm{C}$. However, for the powders of the same size but the spherical shape, the extreme DTG effect was observed at about $1210 \pm 10{ }^{\circ} \mathrm{C}$. Analogous effects occur for a particle size of range $40-56 \mu \mathrm{m}$, but the difference between maximum of DTG peak due to the shape of the particles was then about $10{ }^{\circ} \mathrm{C}$.
Figure 5 presents collected DSC curves recorded for all analysed samples. Regardless of the size and shape of the investigated powders, during their heating, one intense exothermal effect was observed. This phenomenon is related to the oxidation process occurring in the materials. The exothermic peaks that occur in the high temperature (above $1100{ }^{\circ} \mathrm{C}$ ) are possibly related to the oxides formation, which correlates the beginning of the increase in the total mass in the TG curves (Fig. 2).

Similarly as with the TG measurements, it was found that with the increase in the heating rate, the start and end of the exothermic effect were shifted to a higher temperature range. It has also been observed that the energy released during spheroidal particle oxidation is always greater by more than 1.5 times compared to the values recorded during the spongy-shaped particle analyses (Table 4).

Ozawa-Flynn-Wall (OFW) isoconversional methods were carried out to calculate, by performing TG analysis at different heating rates, the activation energy of austenitic stainless steel oxidation process. The activation energy values of spherical powder were almost double as high compared to the values obtained for the spongy particles (Table 5).

The results of DSC, TG and the calculated activation energy values clearly demonstrate a higher resistance to oxidation process of spheroidal than spongy particles. However, upon activation, their oxidation process is much more violent and involves a larger share of spheroidal than spongy powder particles.

Figure 6 shows dimensional changes of samples recorded during sintering. The obtained results demonstrate the significant influence of the size and shape of austenitic stainless steel powders on the sintering process. It was observed that for the spongy particles, the dominance of the diffusion mechanism of matter transport over the thermal expansion of the material occurred at about $953{ }^{\circ} \mathrm{C}$. In contrast, the same effect for the spheroidal particles began at a temperature above about $144{ }^{\circ} \mathrm{C}$. The particle size did not affect significantly to this 

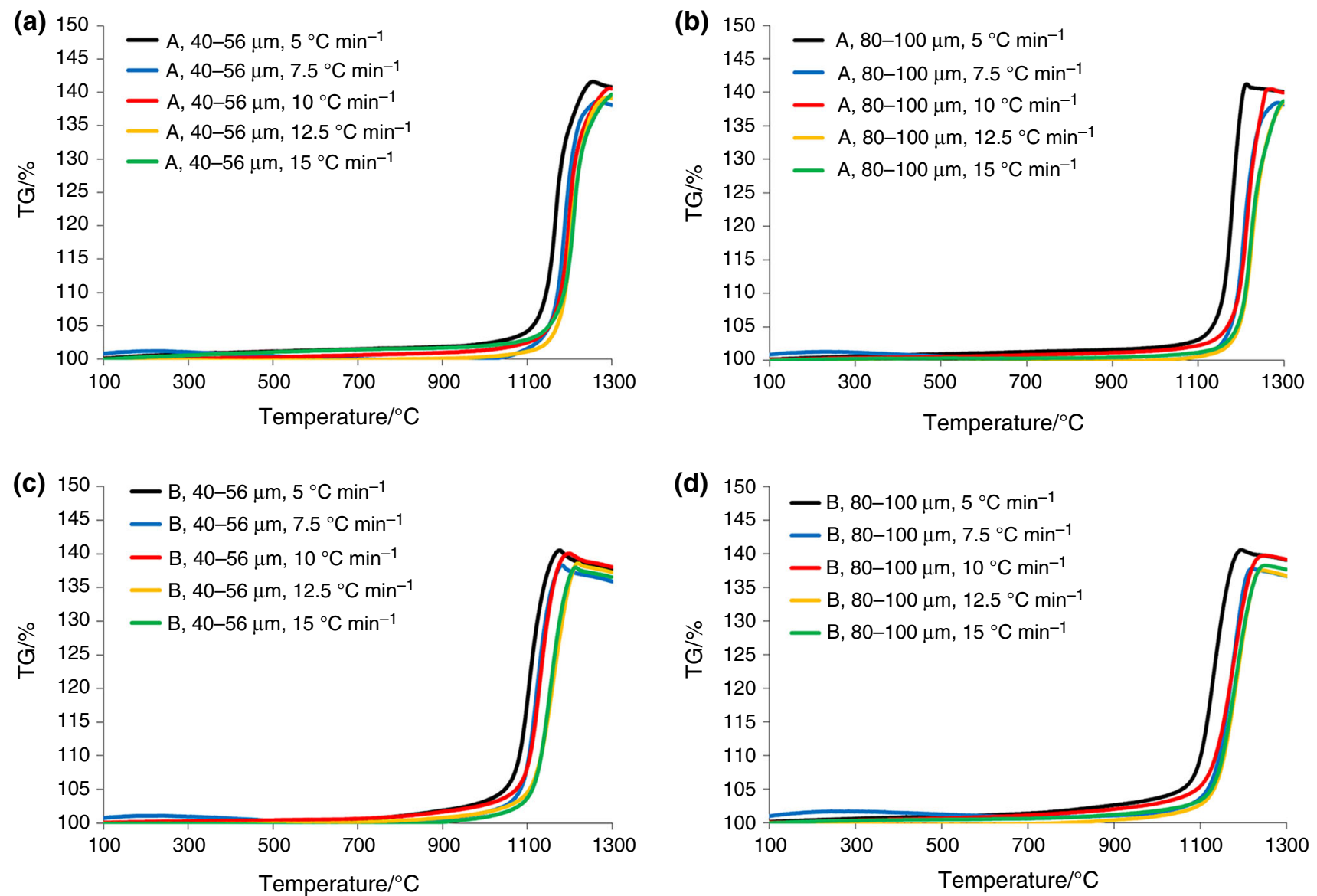

Fig. 2 TG curves depending on the size and shape of the powders as well as the applied heating rate. Notation according to Table 3
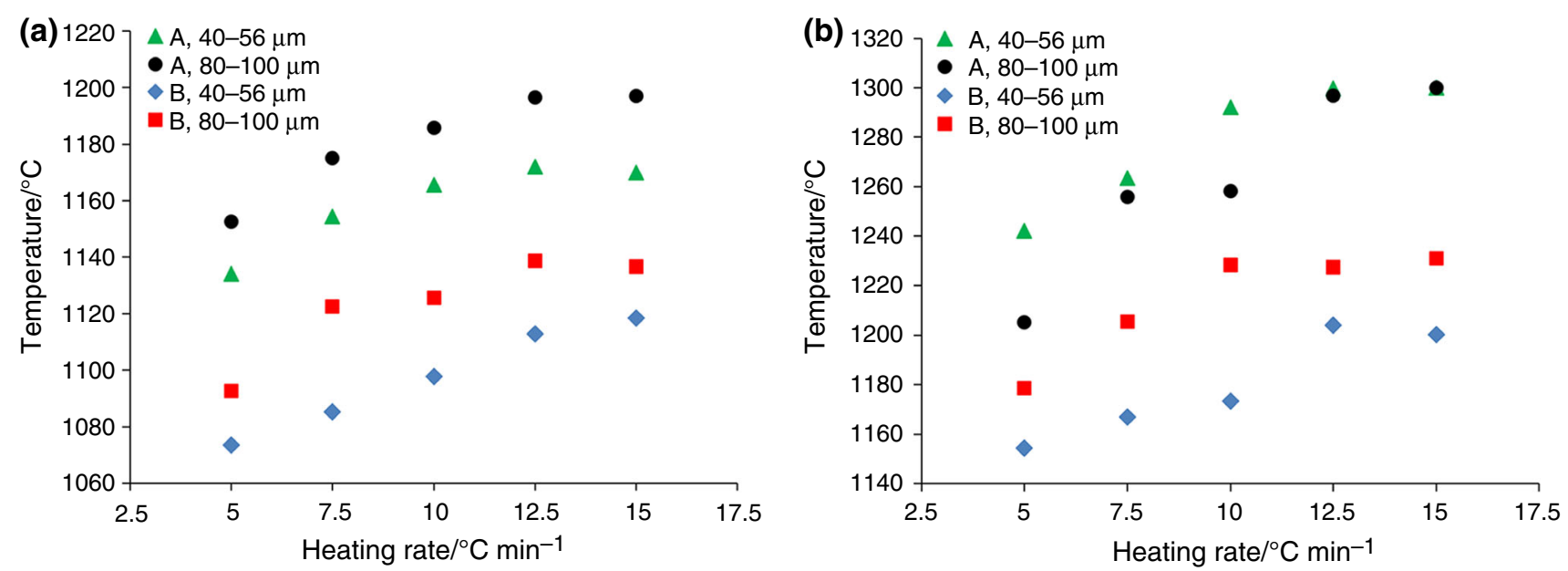

Fig. 3 Values of $\mathbf{a}$ onset and $\mathbf{b}$ endset of the oxidation process depending on the size and shape of the powder particles and the applied heating rate

phenomenon. Furthermore, sinters made of spheroidal particles were characterized more than twice as small as the total shrinkage in comparison with the same sinters but made with spongy particles. In addition, 40-56- $\mu \mathrm{m}$ spongy particles are characterized by higher sintering forces than particle from the range $80-100 \mu \mathrm{m}$. The inverse relationship was observed for spheroidal particles.

Figure 6 presents the dilatometric curves of austenitic stainless steel depending on the size and shape of the powder particles. The shape of dilatometric curves was a 


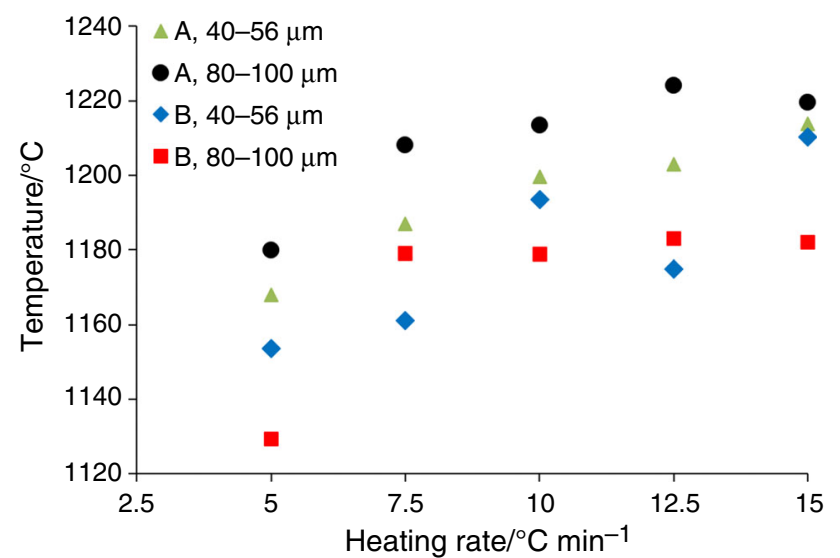

Fig. 4 The temperature of the maximum peak of the DTG curve depending on the size and shape of the powder particles and the applied heating rate

direct consequence of the poorer consolidation of spheroidal powders than the irregular ones. These effects also significantly affect the resistance of sinters to oxidation at elevated temperatures. For samples made from spongy powders, which were more densified during sintering and thus characterized by lower porosity, during the oxidation process, a smaller mass growth was recorded than for sintered powders made from spheroidal particles (Fig. 7). It has also been observed that the sintered samples oxidation process was two-stage, unlike the one-step oxidation mechanism of powders. The first stage of the oxidation process for all investigated sinterings was in the temperature range of $690-1015{ }^{\circ} \mathrm{C}$. As a consequence, the sample mass increased by approximately $4 \%$. The second stage followed immediately after the first one. The end of the second stage was when the cooling step from the isothermal annealing temperature at $1250{ }^{\circ} \mathrm{C}$ started. The total mass growth of the sintered material was $19 \%$ lower than the value recorded during the oxidation of powders. This effect was independent of the type of analysed samples.

The oxidized outer surface has the character of an adherent coating, however, with numerous cracks (Fig. 8), which are a consequence of the increase in temperature and different coefficients of thermal expansion of the formed oxides and steel. It was found that regardless of the size and shape of the powder particles and the applied compaction pressures, the oxidized outer surface of sinters has a similar morphology. Furthermore, observed surface morphology of oxides layer allows to explain recorded
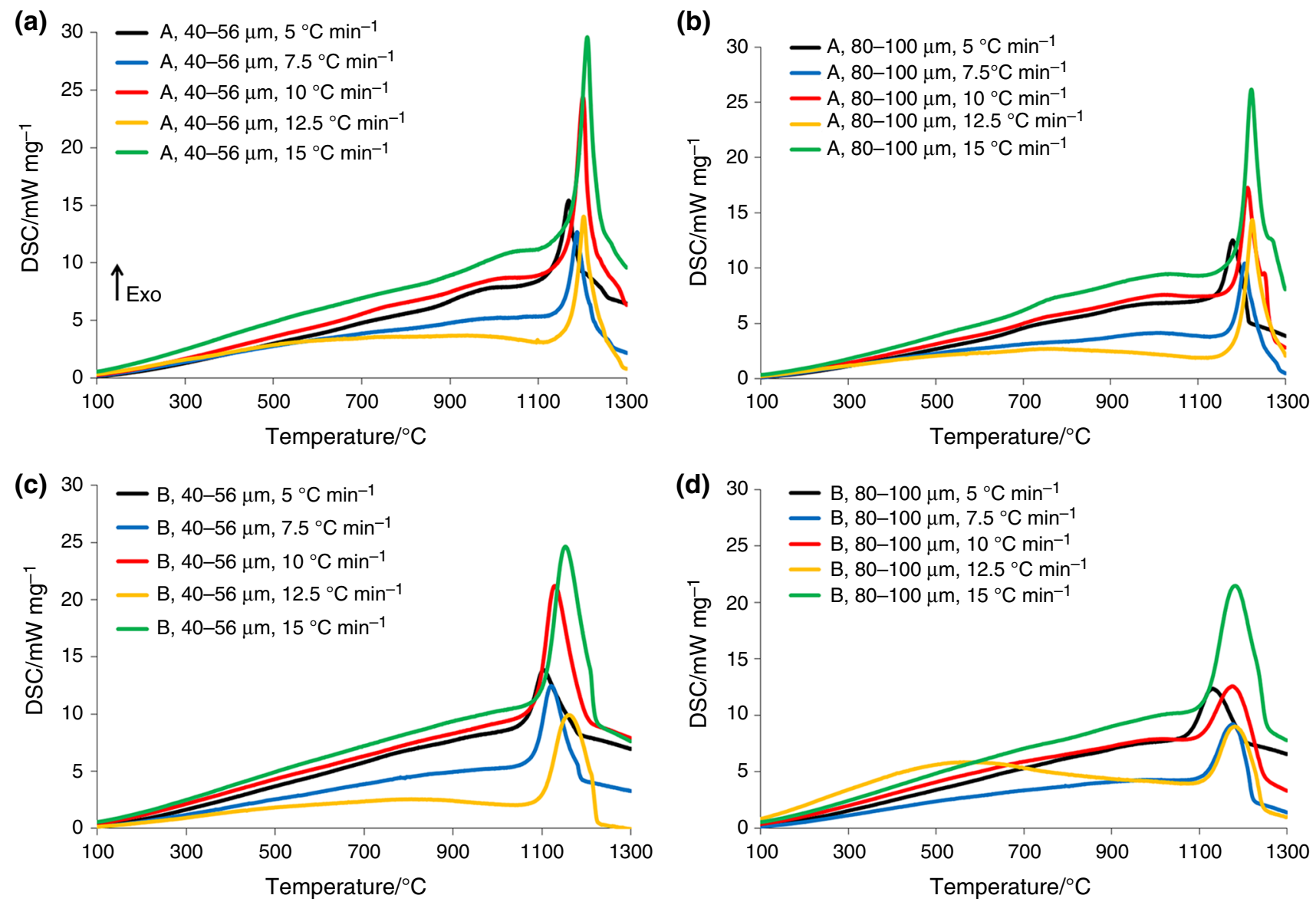

Fig. 5 DSC curves depending on the size and shape of the powders as well as the applied heating rate. Notation according to Table 3 
Table 4 Characteristic values of the DSC curves, depending on the size and shape of the powder particles and the applied heating rate

\begin{tabular}{|c|c|c|c|c|c|}
\hline Symbol of powder & Particles size $/ \mu \mathrm{m}$ & Heat rating $/{ }^{\circ} \mathrm{C} \min ^{-1}$ & Onset $/{ }^{\circ} \mathrm{C}$ & Endset $/{ }^{\circ} \mathrm{C}$ & Peak area $/ \mathrm{Jg}^{-1}$ \\
\hline \multirow[t]{10}{*}{ A (spherical) } & \multirow[t]{5}{*}{$40-56$} & 5 & 1134 & 1203 & 1935 \\
\hline & & 7.5 & 1154 & 1264 & 1957 \\
\hline & & 10 & 1166 & 1229 & 1930 \\
\hline & & 12.5 & 1172 & 1299 & 1987 \\
\hline & & 15 & 1171 & 1247 & 1928 \\
\hline & \multirow[t]{5}{*}{$80-100$} & 5 & 1141 & 1219 & 2893 \\
\hline & & 7.5 & 1175 & 1281 & 2360 \\
\hline & & 10 & 1180 & 1265 & 2515 \\
\hline & & 12.5 & 1197 & 1297 & 2747 \\
\hline & & 15 & 1186 & 1251 & 2969 \\
\hline \multirow[t]{10}{*}{ B (sponge) } & \multirow[t]{5}{*}{$40-56$} & 5 & 1056 & 1184 & 3572 \\
\hline & & 7.5 & 1085 & 1167 & 3544 \\
\hline & & 10 & 1077 & 1215 & 3987 \\
\hline & & 12.5 & 1113 & 1204 & 3535 \\
\hline & & 15 & 1089 & 1224 & 3852 \\
\hline & \multirow[t]{5}{*}{$80-100$} & 5 & 1063 & 1212 & 3937 \\
\hline & & 7.5 & 1123 & 1206 & 3368 \\
\hline & & 10 & 1085 & 1254 & 3398 \\
\hline & & 12.5 & 1139 & 1228 & 3205 \\
\hline & & 15 & 1103 & 1257 & 3822 \\
\hline
\end{tabular}

\begin{tabular}{llll}
\hline Symbol of powder & Shape & Particles size/ $\mu \mathrm{m}$ & Activation energy/kJ mol ${ }^{-1}$ \\
\hline A & Spherical & $40-56$ & 441 \\
& & $80-100$ & 439 \\
B & Sponge & $40-56$ & 351 \\
& & $80-100$ & 206 \\
\hline
\end{tabular}

Table 5 Activation energy depending on the shape and particle size of the powder

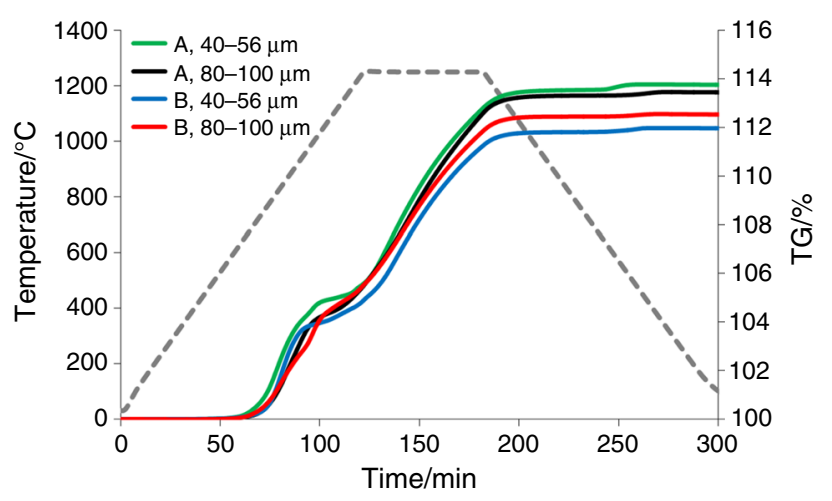

Fig. 7 TG of sintered samples recorded during oxidation, depending on the size and shape of the powder particles

explains the increase in samples mass recorded on TG curves (Figs. 2 and 7) and the exothermic effect on the DSC curves (Fig. 5). The formation of haematite on steel may proceed according to the reaction: $4 \mathrm{Fe}+3 \mathrm{O}_{2}=2$ $\mathrm{Fe}_{2} \mathrm{O}_{3}$, while the magnetite may create according to the reaction: $\mathrm{Fe}+4 \mathrm{Fe}_{2} \mathrm{O}_{3}=3 \mathrm{Fe}_{3} \mathrm{O}_{4}$. Based on the literature, it can be stated that in the first stage of oxidation, less 


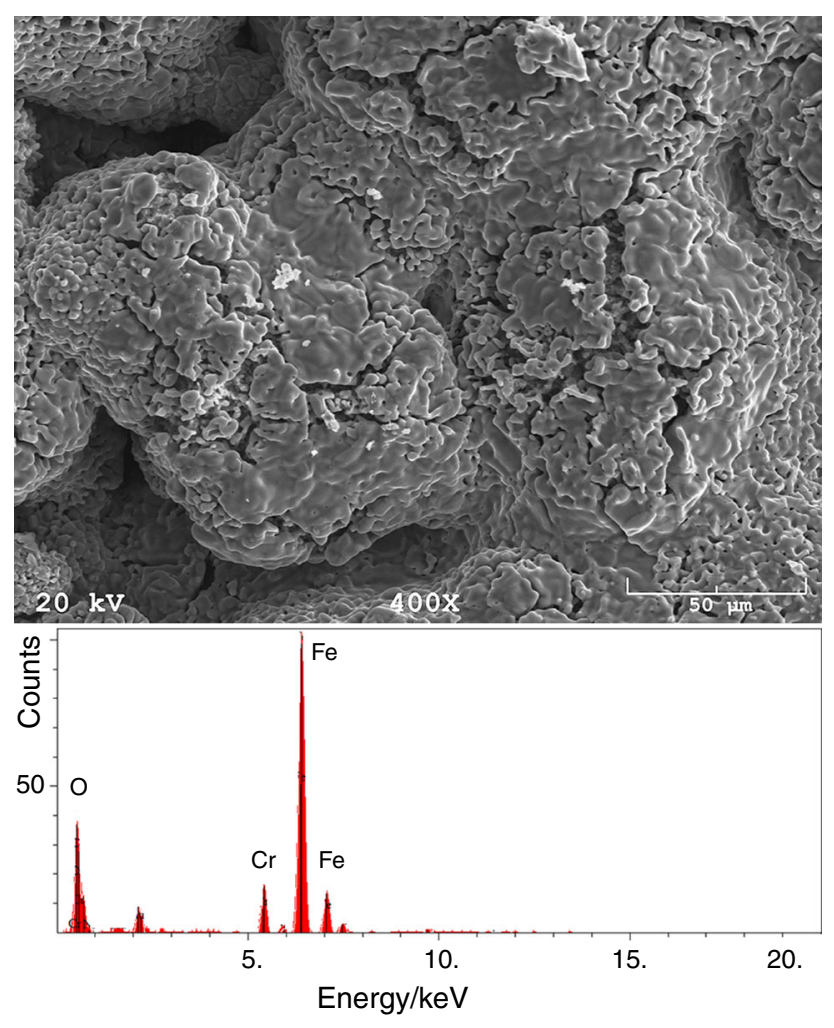

Fig. 8 The surface morphology of oxides layer

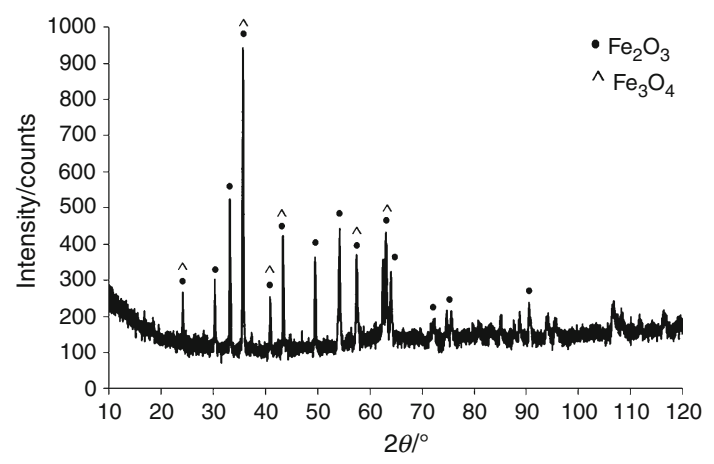

Fig. 9 XRD pattern of oxides layer of sintered stainless steel sample

stable $\mathrm{Fe}_{2} \mathrm{O}_{3}$ oxides form on the surface of the sample. On the other hand, higher temperatures can induce chromium oxides $\left(\mathrm{Cr}_{2} \mathrm{O}_{3}\right)$, solid solution of chromium-iron oxide $(\mathrm{Cr}, \mathrm{Fe})_{2} \mathrm{O}_{3}$ or chromite spinel phases [18-20]. Moreover, chromium can replace iron in the $\mathrm{Fe}_{2} \mathrm{O}_{3}$-type oxide [21].

\section{Conclusions}

Based on the obtained results, it was found that both shape and size of powders have a significant influence on the oxidation processes of powders as well as sinters of the austenitic stainless steel. The initial oxidation temperature of spongy powders, regardless of size, was always lower than for spheroidal particles. Moreover, when the size of powder particles decreases, their oxidation occurs at a lower temperature, regardless of shape. These effects were independent of the applied heating rates. Dilatometric investigations have shown that for spheroidal powders the dominance of the diffusion mechanism of matter transport over the thermal expansion of the material occurs at a higher temperature than that of the spongy particles. In addition, it has been shown that the shape of the powder particles is important for the oxidation resistance of austenitic sinters. It has also been observed that the process of oxidation of powders occurs in one step, while the sinters oxidize into two stages. This effect is related to the densification of the material and necessity of the cracking of the layer of oxides formed on the surface of the sinters which allows further internal oxidation of the sample. This is also confirmed by the fact that sinters made of spongy particles were characterized by a smaller mass growth compared to sintered spheroidal powders. It was also observed that the oxidation of powders is much larger than for the sinters.

Acknowledgements This study was supported by the statutory activity of the Institute of Materials Engineering, Cracow University of Technology.

Open Access This article is distributed under the terms of the Creative Commons Attribution 4.0 International License (http://crea tivecommons.org/licenses/by/4.0/), which permits unrestricted use, distribution, and reproduction in any medium, provided you give appropriate credit to the original author(s) and the source, provide a link to the Creative Commons license, and indicate if changes were made.

\section{References}

1. Amel-Farzad H, Peivandi MT, Yusof-Sani SMR. In-body corrosion fatigue failure of a stainless steel orthopaedic implant with a rare collection of different damage mechanisms. Eng Fail Anal. 2007; 14:1205-17.

2. Brooks EK, Brooks RP, Ehrensberger MT. Effects of simulated inflammation on the corrosion of $316 \mathrm{~L}$ stainless steel. Mater Sci Eng C. 2017;71:200-5.

3. Kurgan N, Varol R. Mechanical properties of P/M 316L stainless steel materials. Powder Technol. 2010;201:242-7.

4. Skałoń M, Hebda M, Sulikowska K, Kazior J. Influence of FeNiMnSiB master alloy on the structure and mechanical properties of P/M AISI 316L. Mater Des. 2016;108:462-9.

5. Qi Q, Liu Y, Wang L, Zhang H, Huang J, Huang Z. One new route to optimize the oxidation resistance of TiC/hastelloy (Nibased alloy) composites applied for intermediate temperature solid oxide fuel cell interconnect by increasing graphite particle size. J Power Sources. 2017;362:57-63.

6. Cho Seungchan, Jo Ilguk, Kim Heebong, Kwon Hyuk-Tae, Lee Sang-Kwan, Lee Sang-Bok. Effect of TiC addition on surface oxidation behavior of SKD11 tool steel composites. Appl Surf Sci. 2017;415:155-60. 
7. Changcong W, Kezhi L, Xiaohong S, Qinchuan H, Caixia H. High-temperature oxidation behavior of plasma-sprayed $\mathrm{ZrO} 2$ modified LaMo-Si composite coatings. Mater Des. 2017;128:20-33.

8. Yi W, Jianhui Y, Dezhi W. High temperature oxidation and microstructure of $\mathrm{MoSi} 2 / \mathrm{MoB}$ composite coating for Mo substrate. Int J Refract Met Hard Mater. 2017;68:60-4.

9. Klar E, Samal PK. Powder metallurgy stainless steels: processing, microstructures, and properties. Materials Park: ASM International; 2007.

10. Ertugrul O, Park HS, Onel K, Willert-Porada M. Effect of particle size and heating rate in microwave sintering of $316 \mathrm{~L}$ stainless steel. Powder Technol. 2014;253:703-9.

11. Menapace C, Cipolloni G, Hebda M, Ischia G. Spark plasma sintering behaviour of copper powders having different particle sizes and oxygen contents. Powder Technol. 2016;291:170-7.

12. Sotomayor ME, Varez A, Levenfeld B. Influence of powder particle size distribution on rheological properties of $316 \mathrm{~L}$ powder injection moulding feedstocks. Powder Technol. 2010;200:30-6.

13. Quanli J, Haijun Z, Suping L, Xiaolin J. Effect of particle size on oxidation of silicon carbide powders. Ceram Int. 2007;33:309-13.

14. Hausnerova B, Mukund BN, Sanetrnik D. Rheological properties of gas and water atomized 17-4PH stainless steel MIM feedstocks: effect of powder shape and size. Powder Technol. 2017;312:152-8.
15. Liverani E, Toschi S, Ceschini L, Fortunato A. Effect of selective laser melting (SLM) process parameters on microstructure and mechanical properties of $316 \mathrm{~L}$ austenitic stainless steel. J Mater Process Technol. 2017;249:255-63.

16. Zhang L, Chen X, Li D, Chen Ch, Qu X, He X, Li Z. A comparative investigation on MIM418 superalloy fabricated using gas- and water-atomized powders. Powder Technol. 2015;286:798-806.

17. Mostafaei A, Hughes ET, Hilla C, Stevens EL, Chmielus M. Data on the densification during sintering of binder jet printed samples made from water- and gas-atomized alloy 625 powders. Data Brief. 2017;10:116-21.

18. Huntz AM, Reckmann A, Haut C, Severac C, Herbst M, Resnde FCT. Sabioni ACS. Oxidation of AISI 304 and AISI 439 stainless steel. Mater Sci Eng A. 2007;447:266-76.

19. Guillamet R, Lopitaux J, Hannoyer B, Lenglet M. Oxidation of stainless steels (AISI 304 and 316) at high temperature. Influence on the metallic substratum. J Phys IV. 1993;3:349-56.

20. Mukherjee A, Jain U, Dey GK. Oxidation studies of Indian reduced activation ferritic martensitic steel. J Therm Anal Calorim. 2017;128:819-24.

21. Hebda M, Gaadek S, Miernik K, Kazior J. Effect of the cooling rate on the phase transformation of Astaloy CrL powders modified with SiC addition. Adv Powder Technol. 2014;25(2):543-50. 